\title{
Beryllium Fluoride
}

National Cancer Institute

\section{Source}

National Cancer Institute. Beryllium Fluoride. NCI Thesaurus. Code C45877.

A white colored, crystalline, inorganic compound that emits toxic fumes of beryllium oxides, hydrofluoric acid and other fluorinated compounds upon heating. Beryllium fluoride is mainly used to produce beryllium metal and alloys and is also used in the production of glass and nuclear reactors. Inhalation exposure to its dust irritates the nose, throat and lungs and can cause pneumonitis. Prolong ed exposure can result in a chronic beryllium disease called berylliosis causing granuloma and fibrosis formation in the lungs. Beryllium is a known carcinogen and is associated with an increased risk of developing lung cancer. ( $\mathrm{NCI05)}$ 